Three rabbits were injected with $20 \mathrm{ccm}$. of the same port reduced to $10 \%$; the animals became inco-ordinate in their movements, lapsed into deep coma, and were all dead in two hours.

Four rabbits were injected with $15 \mathrm{ccm}$. of the same port; slight intoxication came on, and the animals were perfectly normal within one hour and three quarters. Five rabbits were injected with $20 \mathrm{ccm}$. of genuine Rhine wine $(12 \%$ reduced to $10 \%$ ); all of the animals became slightly intoxicated, and 3 were perfectly normal in one hour, 1 lapsed into a coma but was normal in three hours, 1 lapsed into coma and died. Four rabbits were injected with $20 \mathrm{ccm}$. of good claret $(12.5 \%$ reduced to $10 \%)$; marked intoxication set in within a few minutes and all were dead within an hour.

It is evident, therefore, that wine is more toxic than alcohol or whiskey, and that red wines are more toxic than white wines. White wines are manufactured from the juice of the grape alone, while red wines are produced by the fermentation of the entire grape, including the skin and the seed, which contain the essential oils, together with other toxic substances.

From these observations it is evident that the toxicity of alcoholic beverages is not proportionate to the percentage of the alcoholic content, but rather to other substances which they contain. Of the various drinks, the most toxic are the liqueurs and rum. Wine is more toxic than whiskey, and the red wines are more toxic than white wines. Beer and ale are about as toxic as whiskey.

\section{TISSUE NECROSIS FOLLOWING INJECTIONS OF SALVARSAN.}

BY RICHARD L. SUTTON, M.D., KANSAS CITY, MO.

Although salvarsan has not fulfilled the earlier expectations of its discoverer, a fair and impartial trial of the drug in properly selected cases will convince the most skeptical investigator that in this arsenical preparation we possess an agent which is of enormous value in combating treponemal infection.

Ever since the introduction of the new remedy, however, the best method of administering it has been a much discussed question. The principal points to be considered are: (1) The safety of the patient; (2) the maximum benefit to be derived from the use of the drug; (3) the ease and rapidity with which the remedy may be prepared for injection; and (4) the comfort of the patient.

Needless to say, the first factor is by far the most important. If, by employing a particular therapy, we subject our patient to a danger even yreater than that entailed by the disease itself, it were more humane to ignore the special plan of treatment altogether and depend upon safer though possibly less effective means.

Up to the present, salvarsan has been employed intravenously, in alkaline and in acid solution, and subcutaneously and intramuscularly in alkaline and in acid solution, in neutral aqueous suspension, and suspended in oil. Bornstein ${ }^{1}$ has demonstrated that arsenic injected in the form of salvarsan is carried to the liver, kidneys and spleen, and stored there, to be reabsorbed later. He examined several cadavers of individuals dying of intercurrent affections from a fortnight to several months after injection of the drug, and in every instance the result was the same, whether the preparation had been introduced intravenously, subcutaneously or intramuscularly.
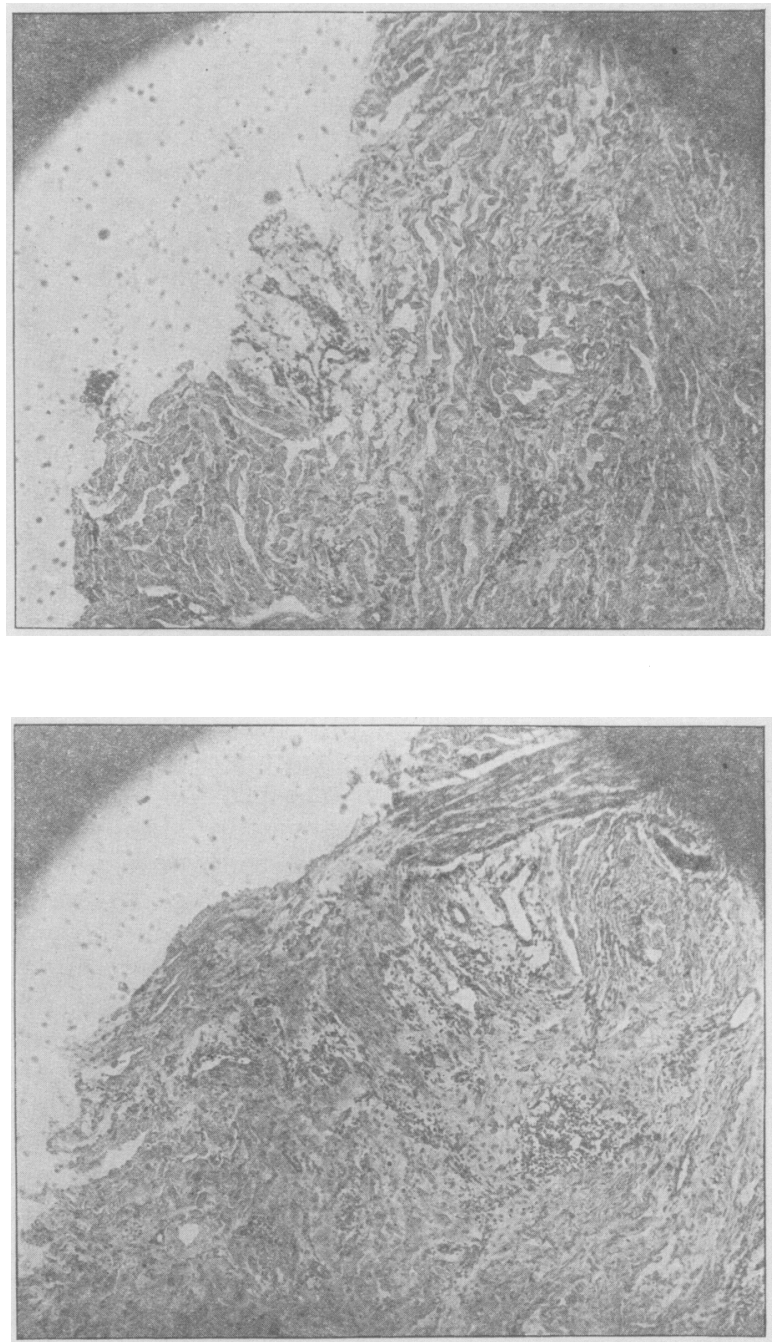

Sections from the wall of a salvarsan abscess showing particles of unabsorbed arsenical material.

The principal advantage of the intravenous route is its comparative painlessness, while the chief disadvantage of this mode of administration is the liability to serious or fatal accidents. When the effect of an improperly prepared solution of salvarsan on the tissues with which it comes in immediate contact is fully appreciated, the majority of operators, and particularly those of wide surgical experience, who have frequently seen alarming symptoms follow so apparently simple a procedure as the intravenous injection

${ }^{1}$ Deut. med. Wochenschr., xxxvii, no. 3. 
of a decinormal salt solution, naturally hesitate before throwing into the circulation a substance which is very liable to give rise to thrombosis and subsequent embolism. Nine recent deaths on the Continent, and two in New York City, all occurring in the practices of able and experienced men, tend to emphasize the fact that such untoward results cannot always be avoided.

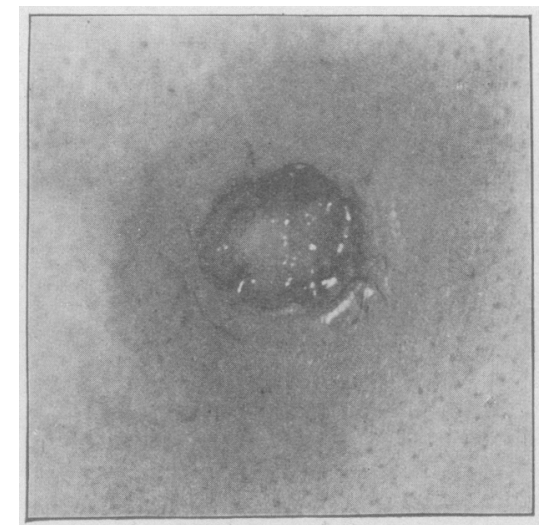

1. Ulcer of the buttock nine weeks after intramuscular injection of oily suspension of salvarsan.

The exact cause of death in these cases is still in doubt. In a recent personal interview, Professor Ehrlich expressed the opinion that the ill-effects were probably due to dead bacteria in the water employed in making the solution, and he now insists that the water be freshly distilled, under the personal supervision of the operator, immediately before use. Needless to add, it is

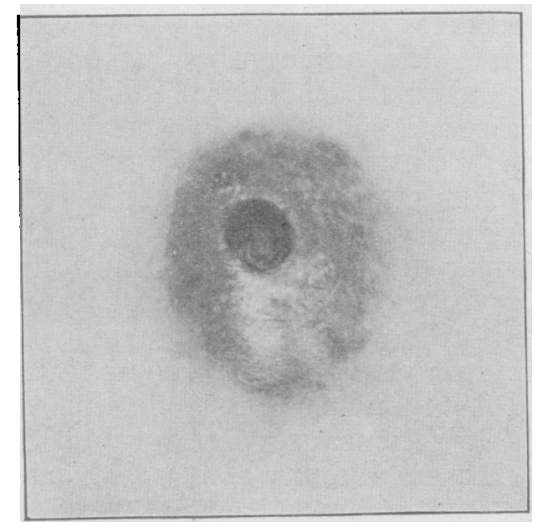

2. Large abscess in scapular region seven weeks after subcutaneous injection of alkaline solution of salvarsan.

essential that the sodium hydrate solution and all of the instruments be carefully sterilized in every instance. Contrary to popular belief, salvarsan is not a direct antiseptic, a fact that has recently been demonstrated by Slusher and Burchell, ${ }^{2}$ and one that can profitably be borne in mind by those medical men who depend upon a druggist for preparing their solutions.

Subcutaneous injections are easily given, but,

2 New York Med. Jour., July 15, 1911. because of the superficial location of the injected material, sloughing of the skin is very liable to occur, and as a rule the patient experiences considerable discomfort for several days or weeks.

The intramuscular method, although slightly painful, is, in my opinion, the safest and, consequently, the best of all.

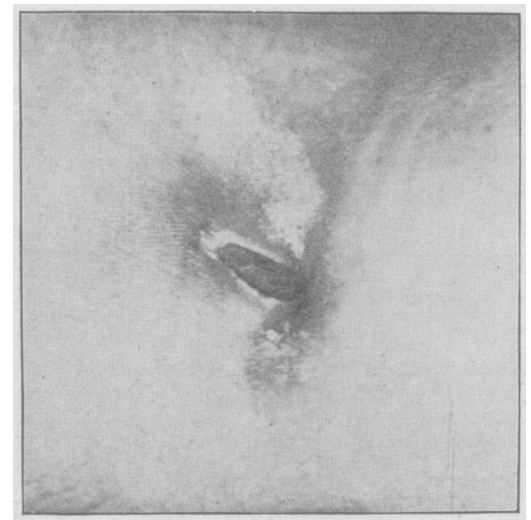

3. Deep ulceration of elbow-joint, with resulting ankylosis, the result of an accident during the intravenous administration of

Through the courtesy of Dr. Simon Flexner, of the Rockefeller Institute, I received a number of doses of salvarsan for experimental study in October, 1910. During the next twelve months I used 397 ampoules of the drug, giving every described method of administration a trial. Since February I have employed only the intramuscular injections (prepared according to the Alt-Lesser technic), and the results have been very gratifying. Up to this time, two of my patients have developed abscesses, but no other untoward effects of any kind have been noted.

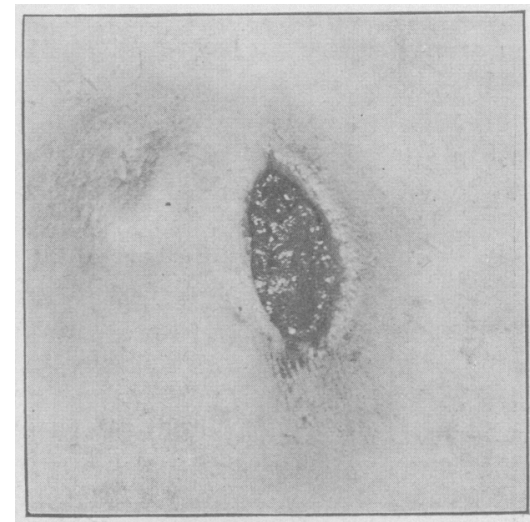

4. Abscess and ulcer in lumbar region three months after an intramuscular injection of improperly prepared alkaline solution of salvarsan.

Sloughing in these cases is evidently not very infrequent, however, no matter how the remedy is administered. At various times during the past five months I have seen more than a score of these lesions. The most serious were those involving the buttock, although one which occurred 
in the elbow-joint had apparently given rise to permanent disability of the limb.

Abscesses result from one of three causes: improper preparation of the solution or suspension employed; insufficiently deep injection of the drug; and bacterial contamination. It is possible that the administration of a dose of the remedy which has undergone oxidation or other chemical change may also give rise to trouble. Fordyce, of New York, informs me that he found three punctured ampoules among the four hundred doses that he has used, and he advises that each container be tested by immersing it in alcohol before removing the contents.

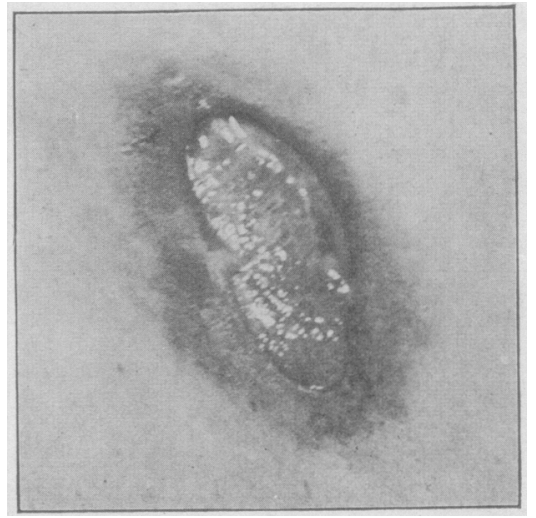

5. Large ulcer of shoulder following subcutaneous injection of alkaline solution of salvarsan.

Examination of the walls of one of the cavities showed an increase of fibrous tissue, with complete blocking of the smaller vessels and lymphatics by minute particles of salvarsan. Numerous small masses of the substance were also found in pocket-like cavities distributed through the section. There were degenerative changes,

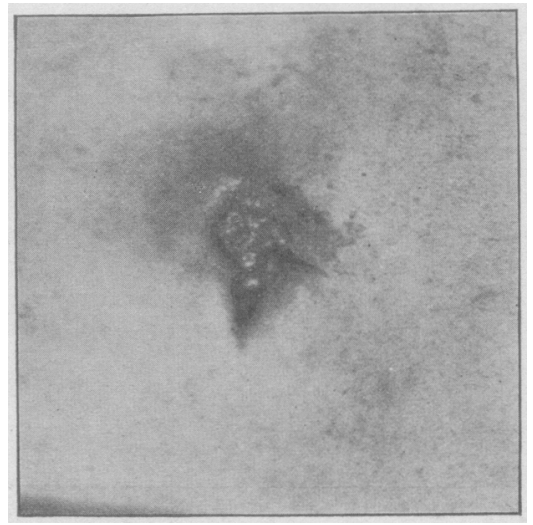

6. Small ulcer in lumbar region following intramuscular injections of salvarsan, probably the result of bacterial infection.

with decrease in amount, of both connective and elastic tissue. In the immediate vicinity of the lesion, evidence of inflammation was almost entirely lacking, and round cell infiltration was conspicuous by its absence. In this instance, it is probable that the drug, which had been em- ployed in supposedly alkaline solution, had not been completely dissolved.

In treating these lesions, I have found it best to dissect or curette out the lining of mummified tissue and allow the cavities to fill up by granulation. Balsam of peru, with an occasional application of copper sulphate or powdered alum, is of value. When the healing process is well established, recourse may be had to an $8 \%$ scarlet $R$ ointment.

\section{Clinital gDepartment.}

\section{A REPORT OF NINE CASES OF OCULAR SYPHI- LIS TREATED BY SALVARSAN ("606").* \\ BY FREDERICK F. CHENEY, M.D., BOSTON.}

Since Ehrlich proclaimed the remarkable virtues of salvarsan in the treatment of syphilis, the subject in its many phases has been so constantly and prominently before the medical profession that a review of the history of its discovery, manner of preparation, methods of administration, etc., is unnecessary in connection with the report of my cases.

The effect of salvarsan upon a syphilitic lesion is, of course, important and interesting to observe and consider. The all-important question, however, is as to whether this drug is a cure for syphilis in the sense that there will be no recurrence of syphilitic lesions at any time in the future. This problem must be worked out by men who have special opportunities not only for treating this class of cases, but for making repeated Wassermann tests and keeping patients under observation for long periods of time. This larger phase of the question cannot be considered in connection with the cases reported, and I can simply note the apparent results of salvarsan upon the existing pathological conditions.

The injection in all the patients treated was given in the buttock. Whether or no the intramuscular is inferior or superior to the intravenous method of injection in point of effectiveness in abolishing or decreasing the syphilitic organisms is still a matter of discussion and probably will remain unsettled for some time to come. The necessary rest in bed, the soreness, often severe pain and occasional abscess following the intramuscular injections are certainly objectionable features that are absent when the salvarsan enters the blood stream direct.

The nine cases that I have to report were treated at the Massachusetts Charitable Eye and Ear. Infirmary. The first four are lesions of the uveal coat, - two of iritis and two a low form of general uveitis, - and the other five are cases of interstitial keratitis.

CASE I. A female, age twenty-six, entered the Infirmary April 18, 1911, with a double iritis. She had had rheumatic symptoms six months before entrance, and the history was so positive that it was at first regarded as a case of rheumatic iritis and so treated.

The right eye had been inflamed for seven weeks

* Read at a meeting of the New England Ophthalmological Society, $*$ Read at a
Nov. 14,1911 . 